of the plant runners to straw. Others state that the Anglo-Saxon name means strayberry, because the runners cause plants to stray from their original location.

Strawberries are relatively unimportant as forage, although some species are rated as fair in palatability for sheep, cattle, deer and elk. The fruits are relished by birds and rodents. The Indians have long esteemed these berries as a delicacy. Records fail to show that strawberries were cultivated by the Romans, who knew these plants exclusively as wild fruit. Stawberries were cultivated in France as early as the fourteenth century, but it was not until the sixteenth century that frequent mention is made of this table delicacy by various European writers, who refer both to the wild fruits and to those cultivated in gardens.

\section{LUMINESCENCE OF FUNGI}

by David Jones, Fort Smith, N.W.T.

On August 19, 1967, I had my first experience with luminescent fungi while camping at Little Buffalo Falls, about 30 miles from Fort Smith, N.W.T.

A friend of mine, Peter Hanson, digging under his sleeping bag in the tent that night, thought he saw a "glowing match". After repeated beatings the "match" didn't go out and he called my attention to it. Within minutes we uncovered a glowing root about a foot long, illuminating the tent in an eerie green light. The root, which appeared dead, was collected and we noted that a live root not more than an inch away emitted no light. I believed that it might be fungus because I had read about luminescent mushrooms of the Philippines.

The next day I took bits of the root to Mr. E. Kuyt of Canadian Wildlife Service, here in Fort Smith, to assist me in identifying it. Mr. Kuyt suggested that it might be the mycelium of Omphalia flavida, and referred me to a description of this phenomenon of luminescence in R. Darnley Gibbs' Botany, an evolutionary approach (Blakiston, Philadelphia, 1950).

I quote from this reference: "An interesting fact, and one the significance of which is not clear, is the luminescence of the mycelia of several fungi. When seen in the dark they glow with a greenish or bluish light which may be quite striking. The author once took home an axe chip about as large as the end joint of one's thumb, containing the mycelium of one of these forms. In a dark room its light was easily sufficient to enable one to read the time from an ordinary watch. The mycelium of Omphalia flavida is particularly useful for the demonstration of this phenomenon. It can be cultured on agar and will glow for weeks."

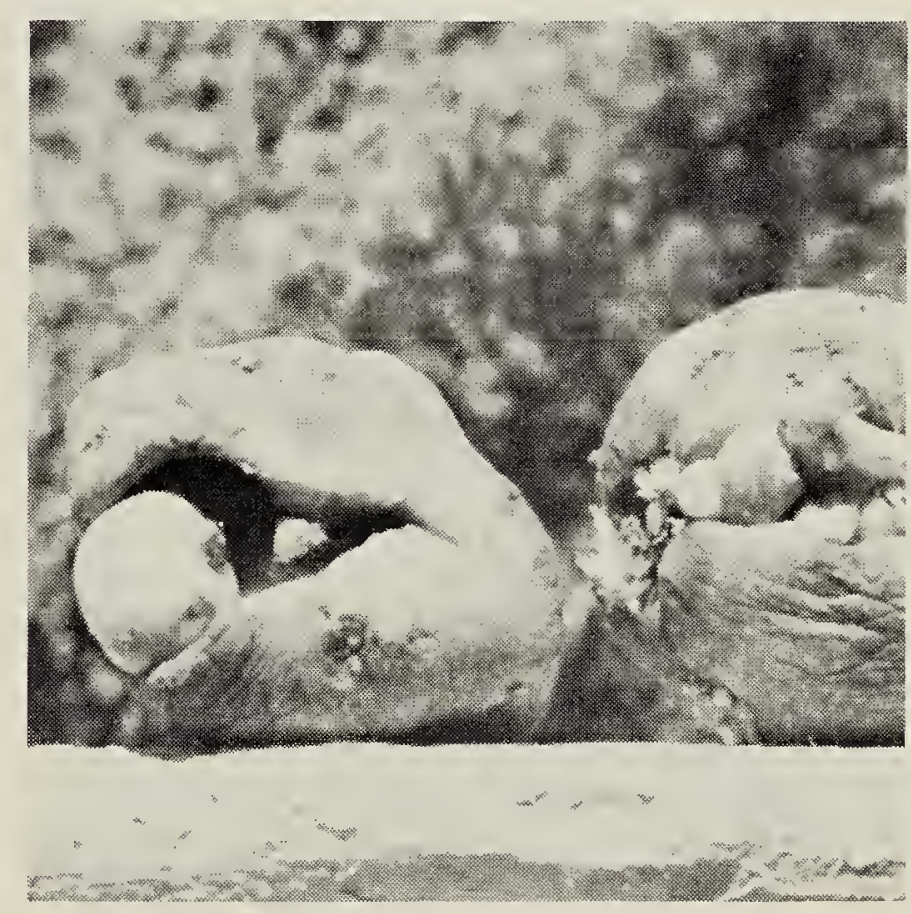

The accompanying photograph was taken of two unusual potatoes that were brought to me by a neighbour, R. W. Bradshaw. These two potatoes from his 1966 crop had spontaneously split in the storage bin and extruded one to five small but well-formed potatoes from the interior. The specimens had been kept for some time, which accounts for their withered appearance.-F. Elmer Wait, 323 Sixth Avenue, Saskatoon. 